\title{
Basic Study on Deformation Evaluation of Steel Wire Mesh for Rational Gabion Structure Design
}

\author{
Hiroshi Nakazawa $^{\mathrm{a}, *}$, Tsuyoshi Nishi ${ }^{\mathrm{b}}$, Hiroyuki Kurihara ${ }^{\mathrm{c}}$, Daisuke Suetsugu ${ }^{\mathrm{d}}$, Tadashi Hara ${ }^{\mathrm{e}}$ \\ ${ }^{a}$ Earthquake Disaster Mitigation Research Division, National Research Institute for Earth Science and Disaster Resilience. Email: \\ nakazawa@bosai.go.jp \\ ${ }^{\mathrm{b}}$ Construction Project Consultants, INC. Email: t_nishi@cpcinc.co.jp \\ ${ }^{\mathrm{c}}$ Kurihara Kenzai Sangyou Co., Ltd. Email: h-kurihara@kurihara-kenzai.co.jp \\ ${ }^{\mathrm{d}}$ Department of Civil and Environmental Engineering Faculty of Engineering, University of Miyazaki. Email: suetsugu@cc.miyazaki-u.ac.jp \\ ${ }^{\mathrm{e}}$ Center for Disaster Prevention Promotion, Kochi University. Email: haratd@kochi-u.ac.jp
}

\begin{abstract}
Gabion structures are used in a variety of ways in Japan and around the world because they allow for the creation of simple structures at highly reasonable construction costs and completion periods. Previous earthquake damage surveys have shown that, in many cases, gabion structures did not collapse even though deformation was allowed, and have demonstrated that the wire mesh used in their construction has a high confinement effect on the stones filling the gabion. Despite this, gabions have not been actively utilized, nor have they been used to construct permanent structures in Japan because the design and construction of such structures are based on experience, and a standardized design method has not been developed. Hence, in order to facilitate development a design method for gabion-based structures, we must first go back to the basics and establish a detailed explanation of the wire mesh deformation mechanism of such structures. In this study, we performed tensile tests on wire meshes of different shapes in order to determine their strength and deformation characteristics and then conducted numerical analyses using the results obtained. The tensile tests revealed that deformation characteristics differed depending on the mesh shape and tensile direction. We also showed that the direction in which the tension acts and the mesh nodes are important, and that the test results could be reproduced via numerical analysis with the finite element method by using beam elements.
\end{abstract}

Keywords: Deformation characteristics; gabion; steel wire mes; , tensile tests

\section{Background}

The origins of gabions have been traced back as far as circa 361-251 BC to the river embankments of the ancient Dujiangyan irrigation system in Sichuan Province, China. They began as cylindrical cages with a turtle-shell-shaped mesh made of bamboo that were filled with quarry stones, cobblestones, and such, as shown in Fig. 1. Today, their use has spread all over the world, and the most commonly used material for the cage has changed to steel, which is more advantageous in many ways, including productivity [1].

The "Guidelines for Galvanized Steel Wire and Structure of Gabions" was established in Japan in April 1953 and the Japanese Industrial Standards for Galvanized Steel Wire Gabions (JIS A 5513) was established in August 1954 to improve and ensure the quality of gabion-based structures [2]. Despite this, there are currently no detailed design

${ }^{*}$ Corresponding author. Tel.: +81-29-863-7308

Tennodai 3-1,

Tsukuba, Ibaraki, Japan, 305-0006 guidelines such as those in concrete and other structures, and there have been very few studies or practical design cases that measure and evaluate the seismic resistance of gabionbased structures while taking into account their beneficial properties such as high flexibility, trackability, and permeability.

Therefore, the designs for gabion retaining walls and similar structures are still supported by road earthwork concrete retaining wall design standards [3]. Hence, in the fields of agricultural and civil engineering works in Japan, gabion-based structures remain a traditional construction method, with almost no track record as semi-permanent structures that make good use of their merits.

Several case examples have confirmed the benefits of gabions such as the abovementioned high flexibility, trackability, and permeability in previous earthquake disasters. For example, after the Gorkha Earthquake that struck Nepal on April 25, 2015, a survey was conducted on road embankment damage in flat areas and slope collapses 


\section{(a)}
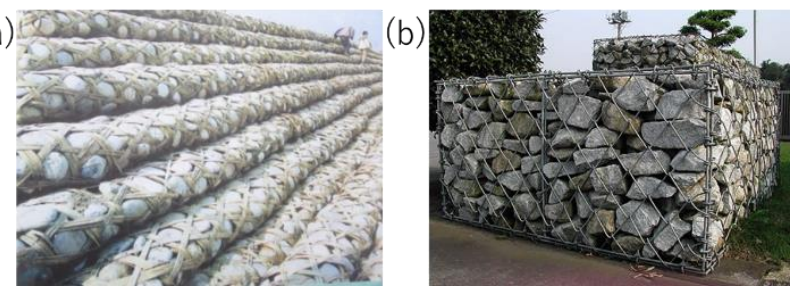

Figure 1. (a) Gabion-based embankment (Photo of a project description board in Dujiangyan, Sichuan Province, China);

(b) Recent Gabion-based structure

in mountainous areas, together with damage to road retaining walls. The findings showed that while there were

Some cases of cracking in concrete retaining walls, the gabion retaining walls were only slightly deformed and did not collapse [4]. According to the report, the gabion-based structures were prevented from collapsing by the confinement effect of steel wires, thereby demonstrating that such structures are highly flexible and persistent.

Consequently, in order to take advantage of this durability and promote the broader use of gabions as a disaster prevention technique, the deformation mechanism of gabions must be determined, and standardized technology for producing gabion-specific designs must be developed. To accomplish these goals, a technological system underpinned by a theoretical background must first be established. In this study, tensile tests and replication analyses performed on wire meshes were conducted to obtain basic data, after which a foundational study was performed as a precursor to establishing a design method.

\section{Significance of This Study Based on Previous Studies}

Following the 2015 Nepal Gorkha Earthquake, a field survey and analysis of the causes of damage to gabion-based retaining walls were conducted, after which shaking table tests using full-scale models were performed. A description of these tests is shown below, followed by a discussion of the significance of this study.

\subsection{Damage survey in Araniko Highway}

Figure 2 shows the survey locations along the Araniko Highway that were investigated after the Nepal Earthquake. For the 115 gabion-based structures along the Araniko Highway, the use, structure, surrounding conditions, gabion dimensions and damage conditions, as well as the grid and wire dimensions, and the filling material quality and dimensions, were all surveyed. The results show that gabionbased structures were used as retaining walls at 56 locations (49\%), as crash barriers at 22 locations (19\%), for riverbank and channel protection, etc. at 17 locations (15\%), for erosion control dams at six locations $(6 \%)$, and as retainment barriers to prevent earth collapse, etc. at 13 locations (11\%). Many of the retaining wall gabion units appeared to have sizes that were adjusted to match field conditions, although their widths, heights, and depths generally measure around $100 \mathrm{~cm}$, and many upright walls had heights of about $3 \mathrm{~m}$.

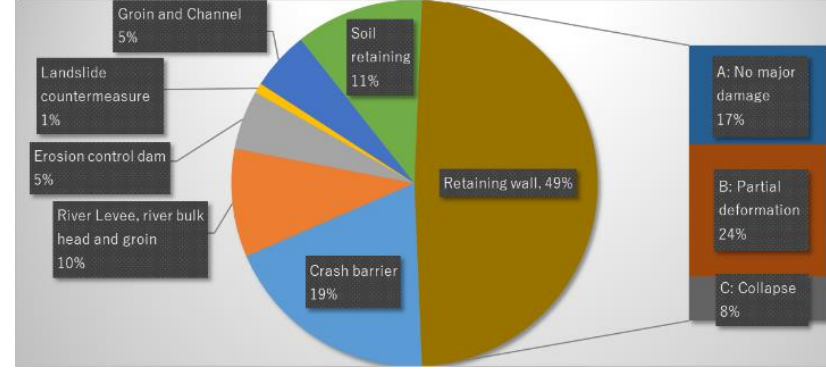

Figure 2. Breakdown of gabion structures along the Araniko Highway (revised from [5])
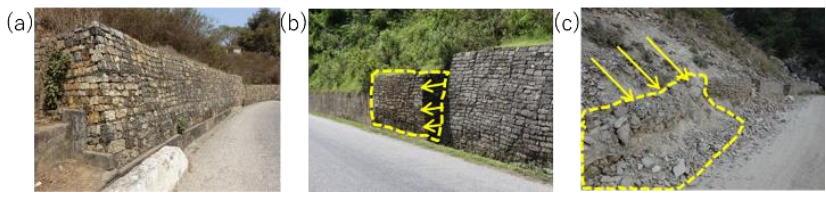

Figure 3. Example of damage; (a) No major damage; (b) Partial deformation; (c) Collapse

Figure 3 shows examples of the damage types observed. Damage patterns were classified into three levels: no damage, partial damage, and collapse, with around $80 \%$ of those surveyed classified as partial or no damage. These findings showed that the minimum road function had been maintained in many cases, which demonstrates the durability of gabion-based retaining walls. Details of the field survey have also been reported by Hara et al. [5].

\subsection{Full-scale shake table test of gabion retaining wall}

A full-scale model experiment was conducted to verify the seismic performance and dynamic behavior of gabionbased retaining walls during an earthquake. This has been reported in detail by Nakazawa et al. [6]. Based on the field survey findings, an experiment was carried out on a retaining wall model with a wall height of $3 \mathrm{~m}$, using gabions with unit sizes of about $100 \mathrm{~cm}$ in width, height, and depth.

For the gabion wire mesh, a rhombus-shaped galvanized product procurable in Japan, with a wire diameter of $3.2 \mathrm{~mm}$ and a mesh $13 \mathrm{~cm}$ long based on the Japanese Industrial Standards (JIS A 5513), was used because it was difficult to obtain the same products used in Nepal. Note that in Nepal, wire diameters range from 3 to $5 \mathrm{~mm}$, and meshes were turtle-shell-shaped, square, or rhombus-shaped, with a minimum mesh size of $9 \mathrm{~cm}$ and a maximum of $18 \mathrm{~cm}$.

In this set of experiments, tests were conducted using three gabion retaining wall types shown as Cases 1 to 3 , one of which consisted of the vertically upright triple-stacked gabion retaining wall common in Nepal and two which involved newly proposed gabion structures [6]. As an example here, the model specifications and test results for Case 1, which show the vertically upright triple stacks common to Nepal, are shown in Figs. 4 to 6.

Shaking was performed by regulating the acceleration amplitude of a $3 \mathrm{~Hz}$ sinusoidal wave in four stages: 65, 132, 203 , and 257 gals. The dynamic behavior results showed that there was a buildup of retaining wall horizontal 
displacement with increased shaking, and that cracks appeared on the ground behind the retaining wall. After the shaking had completely ended, significant forward tilting of the retaining wall and severe ground collapse behind the wall were observed, as shown in Fig. 6.

In particular, there was pronounced deformation on the second layer of gabion and about $80 \mathrm{~cm}$ of horizontal displacement at the top. However, the retaining wall did not collapse even though it tilted about 18 degrees forward. This type of retaining wall deformation was also commonly observed in Nepal. This durability, which is also termed persistence, is believed to be the reason why the wall did not eventually collapse.

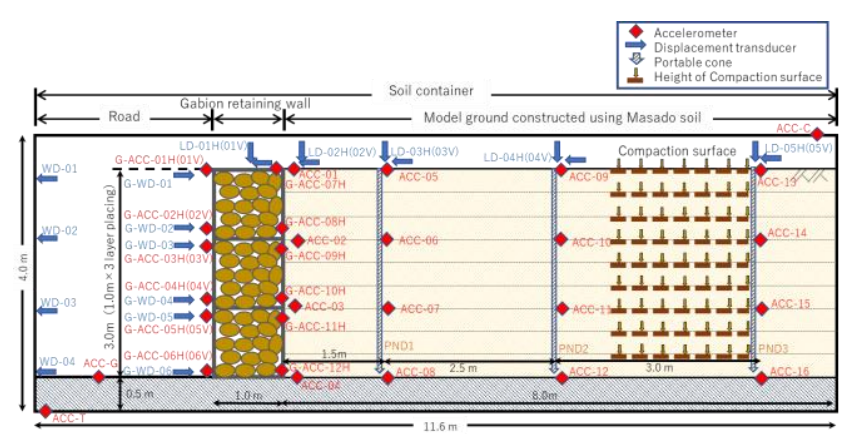

Figure 4. Cross-section of the full-scale gabion retaining wall experiment (revised from [6])

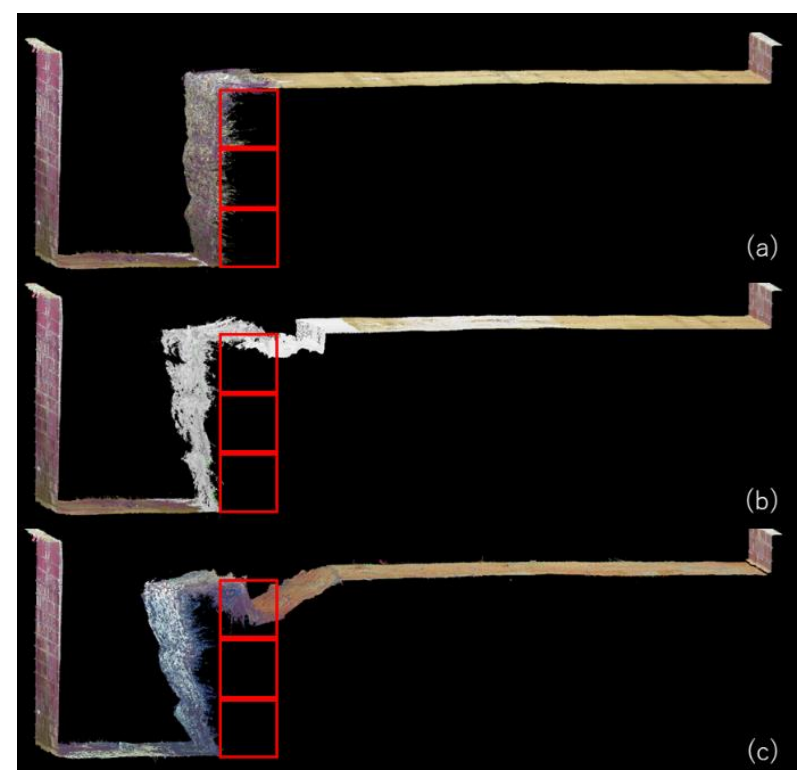

Figure 5. Results of 3D measurements. (a) Before shake test. (b) After shaking at 203 Gals. (c) Residual deformation after final shake test by 257 Gals. [6] The red lines show the original position of the gabion wall

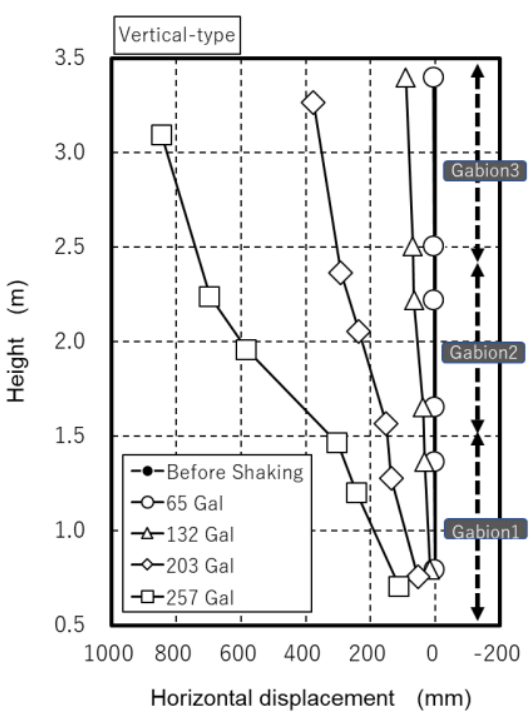

Figure 6. Horizontal displacement of gabion retaining wall front face [6]

\subsection{Purpose of this study}

In the set of surveys and experiments discussed above, emphasis was placed on the filling material and method used for stacking the gabions. The deformation of the gabion retaining wall is thought to be dependent on the deformation characteristics of the filling material and the confinement effect of the wire mesh that restrains it. For example, in Fig. 7 , it can be inferred that the confinement effect of the wire mesh on the front side of the retaining wall is different from that on the rear side. That is, deformation on the front face is considered to be restrained by tensile resistance of the wire mesh on the rear side when bending deformation occurs in the flexible gabion retaining wall structure.

However, mesh shapes and their corresponding deformation and strength characteristics have yet to be studied. In a field trial construction case in Nepal [7], as shown in Fig. 8, the direction of the wire mesh in relation to the assumed direction of retaining wall deformation had not been taken into account, and whether or not this may be a dominant factor remains unclear.

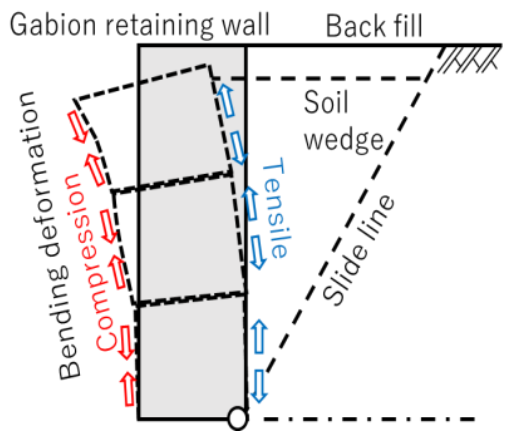

Figure 7. Schematic diagram of gabion-based retaining wall deformation 

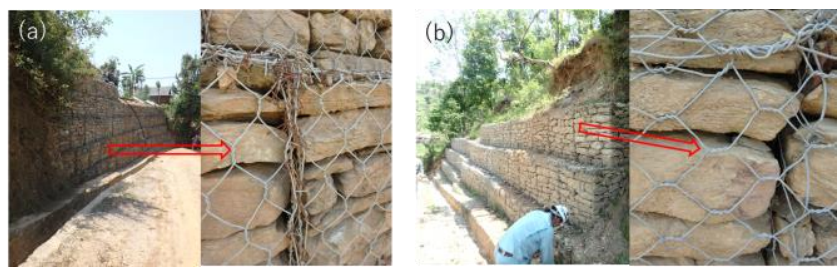

Figure 8. Trial construction of a gabion-based retaining wall [7] The direction of the turtle-shell-shaped wire mesh had not been considered. (a) Mesh line is vertical. (b) Mesh line is horizontal
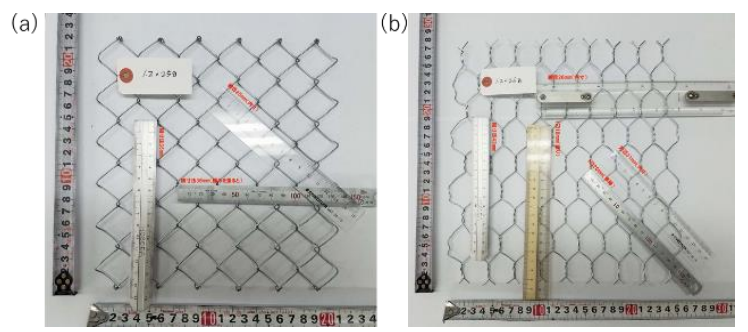

Figure 9. Wire meshes used in the tensile test. The panels consist of $200 \mathrm{~mm} \times 200 \mathrm{~mm}$ galvanized wire with a wire diameter of $1.2 \mathrm{~mm}$

(a) Rhombus-shaped wire mesh. (b) Turtle-shell-shaped wire mesh

The rhombus-shaped wire mesh is common in Japan, although in other countries such as Nepal, the turtle-shellshaped wire mesh is more widely used. Accordingly, to take into consideration the loop shape and friction properties of the wire mesh nodes, tensile tests were carried out using 200 $\mathrm{mm} \times 200 \mathrm{~mm}$ wire mesh with two mesh shape types: rhombus and turtle shell, as shown in Fig. 9, in order to determine their basic mechanical properties.

Moreover, to find out whether the test results can be simulated, a replication analysis using the finite element method (FEM) was performed and the results were examined to determine whether it can be applied to the design of gabion-based retaining walls.

\section{Tensile Test of Steel Wire Mesh}

The tests were conducted in order to determine the mechanical properties of the gabion wire mesh itself. Based on the test results, a replication analysis using the FEM was performed, as will be described in the following section.

Gabions have a simple structure consisting of a steel wire mesh box filled with stones. However, the deformation performance of single gabion units may differ depending on the arrangement of the filling stones. A gabion-based retaining wall is an assembly of gabion units, but the deformation resistance performance of the structure as a whole can be increased by increasing the deformation performance of individual gabion units.

When the gabion unit deforms, it is necessary to examine what kind of wire mesh shape effectively provides the confinement effect and the connection between the filling stones and direction of the wire mesh. After completing this level of study, there will eventually be issues such as the productivity of the most effective mesh types.

Next, in order to take the first step in improving the deformation resistance performance of gabion structures as a whole, tensile tests were conducted to determine the basic mechanical properties of gabion wire meshes according to the mesh shape differences. Table 1 shows the test cases. Basically, the objective of this test was to compare mesh shapes and tensile direction, although differences in loading rates were also investigated. The effect of the loading rate was also checked because rearrangement, strength development, etc. may possibly occur depending on the rate, even if the structure breaks partially during tensioning.

\subsection{Specification and properties of steel wire mesh}

The wire specimen used in the tensile test was a $1.2 \mathrm{~mm}$ diameter galvanized steel product, from which panels were fabricated with a mesh size of $200 \mathrm{~mm} \times 200 \mathrm{~mm}$, as shown in the lower part of Table 1 . The tensile strength of the wire was 350 to $380 \mathrm{~N} / \mathrm{mm}^{2}$.

Using the test apparatus shown in Fig. 10, tensile tests were carried out after running bolts through the edges of the wire mesh and fixing them in place. Note that due to the difference in shapes between the rhombus and turtle shell meshes, the number of bolts secured at the edges depends on the mesh shape and could not be standardized. In this paper, the test results were evaluated by comparing the tensile behavior with respect to the relationship between the applied tensile force $\mathrm{T}(\mathrm{kN})$ and the stroke of the testing apparatus. In principle, the rate of tensioning used was $40 \mathrm{~mm} / \mathrm{min}$ using displacement control. For Case 1, the test was also conducted at $10 \mathrm{~mm} / \mathrm{min}$ in order to investigate the dependence on the loading rate.

Table 1. Tensile test cases. The indicates bolt fixing positions

Case1 (a)

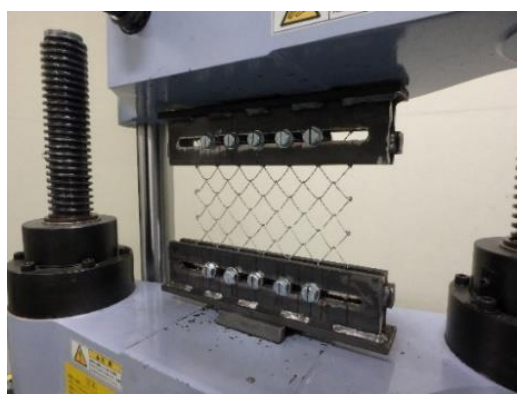

Figure 10. Test apparatus 


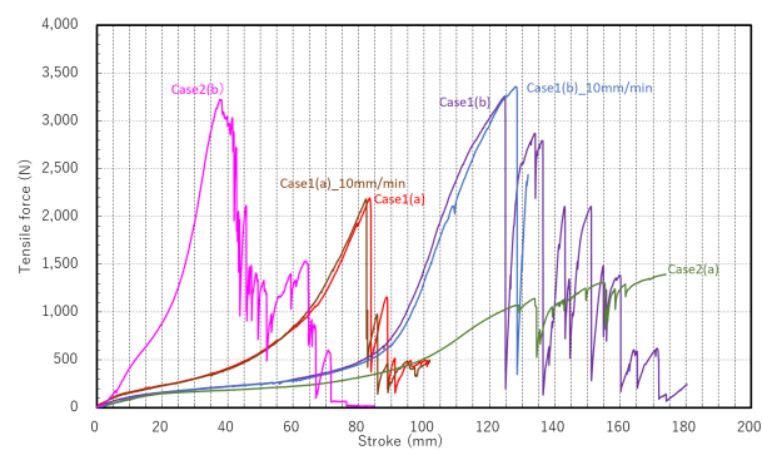

Figure 11. Results of tensile tests

(a)
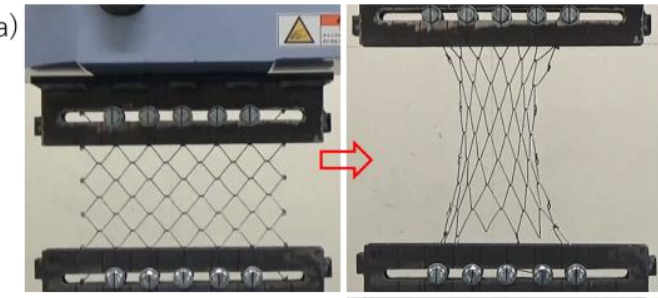

(b)
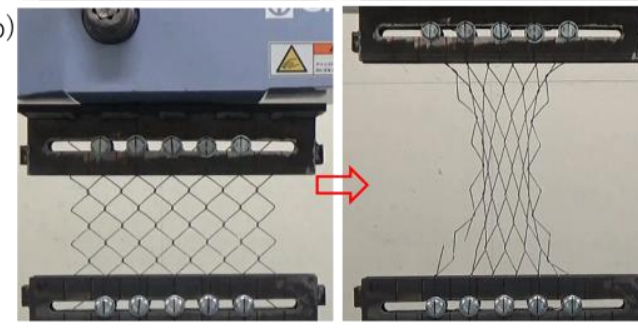

(c)
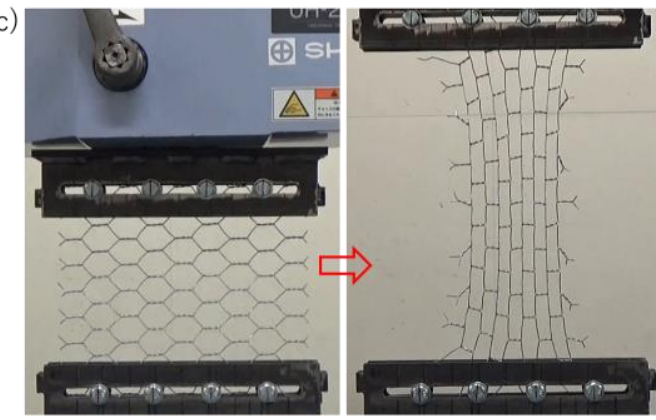

(d)

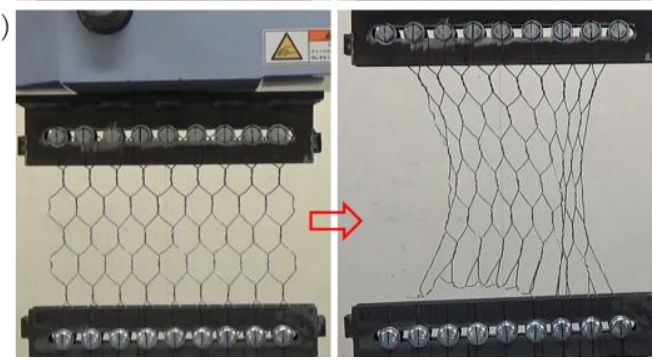

Figure 12. Shapes before and after Tensile tests. (a) Rhombus shape (Case 1(a)). (b) Rhombus shape (Case 1(b)). (c) Turtle shell shape (Case 2(a)). (d) Turtle shell shape (Case 2(b)) in Table 1

\subsection{Results of tensile tests}

Figure 11 shows the test results for all cases, while Fig. 12 shows photos of post-testing wire mesh deformation. For the effect of tensioning rates, which was tested in Cases 1(a) and (b), there were no differences in results observed between $10 \mathrm{~mm} / \mathrm{min}$ and $40 \mathrm{~mm} / \mathrm{min}$. Therefore, only the test results from a tensioning rate of $40 \mathrm{~mm} / \mathrm{min}$ are discussed in this paper.

Looking at Case 1 with a rhombus shape, we see that the load-displacement relationship did not change regardless of the direction of the wire mesh. However, Case 1(a) carries a more significant portion of the tensile force at the mesh nodes than (b), so the tensile load developed early and the edges ruptured significantly, thus causing the peak value to be small. Although both of these cases showed a dramatic decrease in tensile force after peaking, it can be seen afterward that the nodes that did not rupture cycled between tensile loading and rupture until reaching their ultimate state. As a whole, their post-test deformation characteristics did not appear to be significantly different from each other, as shown in Fig. 12.

In contrast, for Case 2 with the turtle-shell-shaped wire mesh, it can be seen that the pattern of the load-displacement relationship is completely different depending on the tensile direction. For (b), in which the twists are parallel to the tensile direction, it can be seen that the tensile loading developed at the smallest level of displacement. In this case, the mechanism does not involve taking up the tensile force at the nodes as in Case 1, and the deformation does not seem to have loosened the twists, thereby suggesting that friction at the twists is the dominant factor.

For (a), the twists are perpendicular to the tensile direction. After the test, Figure 12 shows that the mesh shape deformed into rectangles with the twists on the short side. From the load-displacement relationship shown in Fig. 11, it can be seen that although the effect of ruptures can be observed, the tensile force did not peak as it gradually increased with the increased displacement, even at displacement levels where the test ended for other cases.

\section{FEM Analysis for Tensile Tests of Steel Wire Mesh}

When evaluating the stability of gabion-based retaining walls, it is crucial to verify the confinement effect of the wire mesh on the filling material. In the FEM analysis, a replication analysis of the tensile test results was performed in order to determine the mechanical properties of the gabion wire mesh. By comparing the deformed shape between the replication analysis and the test results, the validity of the FEM model could be checked and model improvements were identified.

\subsection{Analysis cases and modeling}

Similar to the test cases shown in Table 1, the rhombusshaped and turtle-shell-shaped wire mesh diagrams are shown in Fig. 13. The member was considered as a linear elastic body, and the load was applied to nodes at the upper end while the lower end was fixed. Table 2 shows the physical properties of the steel wire mesh material.

The nodes are a vital requirement in the modeling. The rhombus shape was given uniform dimensions overall. In contrast, because the turtle shell shape twisted parts have two twined wires, the cross-sectional area and moment of inertia were doubled. 
Table 2. Physical properties of the steel wire mesh model.

\begin{tabular}{l|c}
\hline Diameter $(\mathrm{mm})$ & 1.2 \\
\hline Cross section $\left(\mathrm{m}^{2}\right)$ & $1.131 \mathrm{E}-06$ \\
\hline Moment of inertia $\left(\mathrm{m}^{4}\right)$ & $1.018 \mathrm{E}-13$ \\
\hline Torsional moment $\left(\mathrm{m}^{4}\right)$ & $2.036 \mathrm{E}-13$ \\
\hline Young's modulus $\left(\mathrm{kN} / \mathrm{m}^{2}\right)$ & $2.000 \mathrm{E}+08$ \\
\hline Poisson's ratio & 0.30 \\
\hline Unit weight $\left(\mathrm{kN} / \mathrm{m}^{3}\right)$ & 77.0 \\
\hline
\end{tabular}

(a)

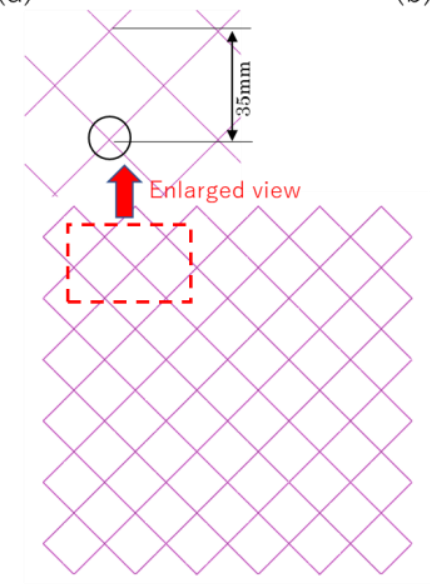

(b)

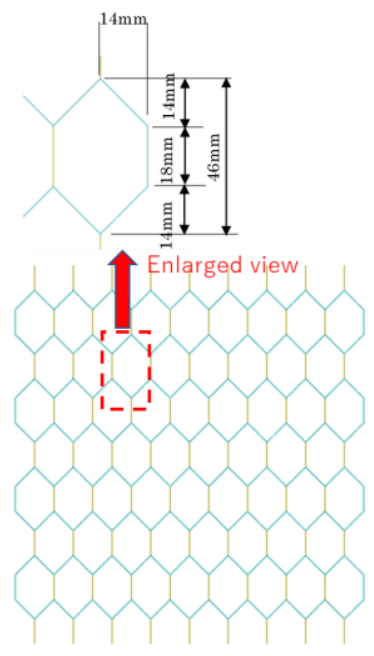

Figure 13. FEM models. (a) Rhombus shape. (b) Turtle shell shape

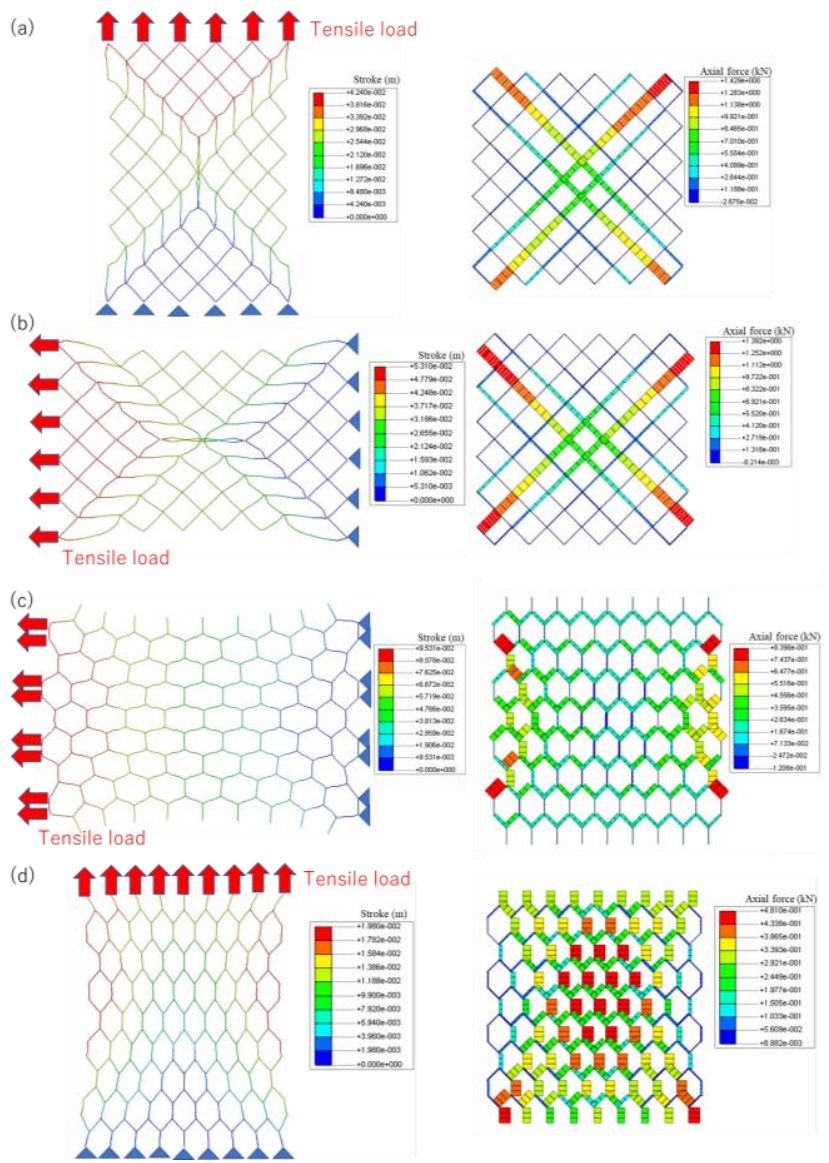

In the replication analysis of the rhombus-shaped wire mesh, joint springs were set at the intersecting points shown by the circle in Fig. 13. The spring properties were $1.0 \times 10^{7}$ $\mathrm{kN} / \mathrm{m}$ in the $\mathrm{y}$-direction and $1.0 \times 10^{3} \mathrm{kN} / \mathrm{m}$ in the $\mathrm{x}$ direction. In other words, the joint was fixed when loaded in the y direction, while slipping occurred when loaded in the $\mathrm{x}$-direction.

For the turtle-shell-shaped mesh, when loading in the direction of the mesh line, the lower end was fixed while the upper end was loaded at nine points with the load increasing by $1 \mathrm{kN}$ increments in each of the 100 steps. When loading in the direction perpendicular to the mesh line, the loading points were set as eight points at the hexagonal vertices with $1 \mathrm{kN}$ applied in 100 steps at each point same as the case loading in the direction of the mesh line.

\subsection{Results of FEM analysis}

Figure 14 shows the deformation and axial force diagrams based on the analysis for each case. Looking at the results on the 50th step with $3.0 \mathrm{kN}$ for Case 1(a) and (b) with the rhombus-shaped mesh, it can be seen that loading in the $\mathrm{x}$ direction has a slightly larger deformation, but the axial force acting in the $\mathrm{x}$-direction is larger. On the other hand, looking at the results of 37 steps with $2.96 \mathrm{kN}$ acting in Case 2 with the turtle-shell-shaped mesh, we can see that the value of the loads in (a) and (b) are almost the same, but the amount of deformation in (b) is much larger than in (a), and the axial force is nearly double.

The above results show that for the turtle-shell-shaped wire mesh, in particular, the highly anisotropic property, in which the deformation characteristics differ depending on the direction of the acting tensile force, can also be expressed by numerical analysis.

\subsection{Comparison of results between analysis and tensile tests}

Similar to Figure 11, which summarizes the tensile test results, Figure 15 shows a summary of the numerical analysis results. Looking at the relationship shown in 15(a) between the displacement until $2 \mathrm{~mm}$ stroke and the tensile force, we can see that the tendency for tensile resistance to develop and the deformation performance for all the cases are similar in both the test results and the analysis results. In both, the deformation of (a) is larger than (b) in Case 1 as well as in Case 2.

On the other hand, for the build-up after loading, it can be seen that, overall, the analysis results are larger than the test results. This may conceivably be due to the fact that the analysis used elastic analysis and that in the test, looseness occurred at the wire mesh crossings, which means that large acting forces were not generated at the initial stage of loading until those loose sections were closed and tensile resistance was exerted.

Figure 14. FEM model 

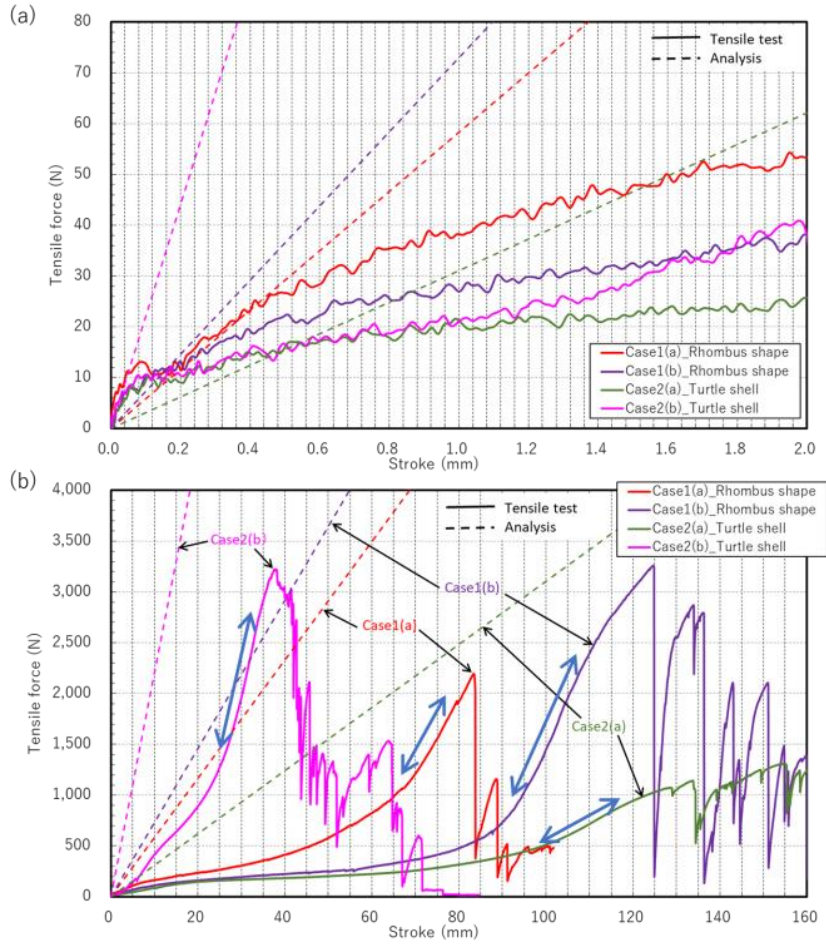

Figure 15. Comparison FEM analysis and Tensile test results.

Next, looking at Fig. 15(b), it can be considered that deformation performance in the tensile test results, from the development of tensile resistance until the start of partial rupture or damage (indicated by $\leftrightarrow$ ), is not significantly different from those in the analysis results. In actual gabions, the filling material is granular and is not self-supporting, so there are always tensile forces acting on the wire mesh at the sides of the structure. Therefore, the fact that deformation performances are consistent between the analysis results and the tensile test results for the section indicated $(\leftrightarrow)$, in which the stiffness has recovered in the tensile tests, may be considered to be a very significant finding of this study.

\section{Conclusion}

Gabions have advantages, such as high flexibility, trackability, and permeability, which means that highly disaster-resistant gabion-based structures that will not collapse even when deformed can be built. However, a design system has not yet been established because their mechanisms remain unclarified. In this study, tensile tests and replication analyses were conducted on wire meshes to obtain basic data, after which a foundational study was performed as a precursor to establishing a design method.

From a series of test results, it was found that, regardless of shape, wire meshes had strength anisotropy depending on the tensile direction, and that both types of wire mesh examined in this study displayed tensile properties that showed stronger behavior in the direction of the mesh line. For the turtle-shell-shaped wire mesh, friction at the twists formed by winding the wire three times was found to be the dominant factor resisting tension, and the results showed that its anisotropy is stronger than the rhombus-shaped wire mesh, which is only hooked at the looping point.

On the other hand, in the replication numerical analyses performed for the above tensile test results, because a certain amount of displacement is needed until tensile resistance is exhibited for all of the test results, it is difficult to interpret a direct comparison with linear analysis, which has stiffness from the initial stage. However, the relationship between the amount of displacement and tensile force showed that, in the elastic deformation range in which looseness in the wire mesh has disappeared and stiffness has recovered in the tensile test, there was consistency between the test and analysis results in each case. This suggests that the wire mesh can be modeled and simulated until it becomes damaged or ruptured.

The above findings provided an understanding of a part of the fundamental behavior of wire meshes. Moving forward, a design method will have to be created through the development of a tensile strength evaluation method that considers factors such as the wire mesh thickness, the number of nodes, and the amount of wire used. Additionally, it will be necessary to develop a method for determining the mesh direction for the wire mesh that considers the direction of external force and the deformation characteristics of the filling material.

\section{Acknowledgments}

The authors express sincere appreciation to the support by the Ohata-Foundation for the help in carrying out tensile tests reported in this study.

\section{References}

[1] Japan Jakago Association. Guide and commentary on gabion engineering method, 2008. [in Japanese]

[2] Association of Nationwide Disaster Prevention and Japan River Association, Knowledge of gabion, 1963. [in Japanese]

[3] Japan Road Association. Road Construction Works on Soil Retaining Wall Guidelines, pp.97-109, 2012. [in Japanese]

[4] Nakazawa, H., Manandhar, S., Hara, T., Suetsugu, D., Kuribayashi, K., Nishi, T., Sakuraba, T., Kariya, T., Ko-chi, Y. and Hazarika, H. Report on damages caused by the 2015 Nepal Gorkha Earthquake, JAEE International Symposium on Earthquake Engineering, P2-36, 2015.

[5] Hara, T., Nakazawa, H., Suetsugu, D., Kuribayashi, K., Nishi, T., Tadokoro, Y., Miyoshi, K. and Zhang, H. Field survey on damages of gabion structures caused by the 2015 Nepal Gorkha Earthquake and examination of specific measures for earthquake resistaance improvement, Journal of Japan Society of Civil Engineers, Ser. A1 (Structural Engineering \& Earthquake Engineering), Vol.74, No.4, pp. I_586-597, 2018. [in Japanese]

[6] Nakazawa, H., Hara, T., Suetsugu, D., Nishi, T., Kuribayashi, K., Miyoshi, K. and Shimomura, S. Experimental evaluation on earthquake-resistance of road retaining wall using gabion, Journal of Disaster Research, Vol.13, No.5, pp.897-916, 2018. (doi: 10.20965/jdr.2018.p0897)

[7] Kimura, S., Hara, T., Suetsugu, D., Nakazawa, H., Nishi, T., Shimomura, S., Shibahara, R. and Kuribayashi, K. An issue of seismic structure and construction regarding gabion wall in rural area of Nepal, Proc. of 7th Asia Conference on Earthquake Engineering, No.0151, pp.1-10, 2018. 